\title{
NOTAS DE OLIGARQUÍA MORISCA GRANADINA. LA FAMILIA FERÍ
}

\author{
Camilo Álvarez de Morales*
}

La lectura de documentos conservados en archivos granadinos nos da noticias de la familia Ferí, que por su importancia económica, por el hecho de percibir alguno de sus miembros salario real y por la participación de otros en asuntos que interesaban a la sociedad morisca del reino de Granada, permiten encuadrarla entre las familias que se situaban en la minoría morisca dominante.

Hasta el momento nos son conocidas tres generaciones de la familia Ferí, con Hernando "el viejo" como cabeza visible y primero de su casa que destacó por su influencia y su poder económico, con intereses en distintos puntos de la ciudad, junto a su yerno Lorenzo el Chapiz, coordinador de un "negocio general", de delimitaciones no del todo precisas, que involucró a la Corona de Castilla, a la Inquisición y a los moriscos de todo el reino, hasta llegar al último conocido, otro Hernando Ferí, perceptor de un salario real indicativo de servicios prestados al poder castellano. Son testimonio de que esta familia mantuvo a lo largo del siglo XVI una presencia constante en el mundo morisco granadino, acreditada por la documentación pertinente, inédita en gran parte.

\section{HERNANDO EL FERÍ, "EL VIEJO”}

El personaje más relevante de la familia fue Hernando el Ferí, mercader, empadronado en la parroquia de San Pedro y San Pablo, dueño de casas, tiendas y tierras en Granada y fuera de ella ("bienes y hazienda, tratos y casas y caudales"1), que debían proporcionarle rentas sustanciosas, hasta el punto de figurar entre los prestamistas a la Corona de Castilla, teniendo constancia de que en 1545 su aportación suponía un montante de 76.500 maravedís $^{2}$. Fue, además, repartidor de farda de la parroquia de San Blas, en el Albaicín.

\footnotetext{
* $\quad$ Escuela de Estudios Árabes (CSIC), Granada.

1. Archivo Municipal de Granada, legajo 3.430, p. 20, fol. 4v.

2. Cf. M. GARZÓn PAREJA, Historia de Granada, Granada, Diputación Provincial, 1981, vol. II, p. 33.
} 
Entre los bienes que hemos podido constatar como suyos, figuran la vivienda del Albaicín y una tienda en la Alcaicería por la que pagaba de censo perpetuo al Hospital Real tres reales y dos gallinas cada año ${ }^{3}$. La había adquirido a Alonso Fernández Moroxí y medía "vara y media de largo y dos varas y quarta de ancho sin el gordor de las paredes"4. Hay datos de otra tienda, distinta de la anterior a juzgar por las medidas ("tiene por lo largo de la puerta quatro varas y media y desde la puerta hasta la pared frontera tiene cinco varas y media y de alto tiene quatro varas"), que tenía alquilada al Licenciado Castillo ${ }^{5}$, según datos que figuran en el libro de apeo de los bienes de la renta de la hagüela ${ }^{6}$ de 1552.

Por orden cronológico, las primeras noticias que tenemos sobre él se refieren a un pleito sobre aguas, junto a otros propietarios de casas en el Albaicín, contra Francisco de Padilla, juez de aguas y administrador de las mismas, quien había mandado ejecutar la obra de un caño que unía la acequia del Arrabal de Albaida con la de la Alcazaba ${ }^{7}$, obra que, a juicio de los demandantes, dañaba sus derechos, y que en el caso del Ferí se referían al riego de la huerta de su casa. Los años que se consignan en tal pleito van de 1525 a $1531^{8}$. Los jueces se personaron en la Puerta de Fajalauza, en donde se hacía el reparto de las aguas del Albaicín, y con ellos el escribano mayor y el propio Francisco de Padilla, además de otros testigos. Por su parte, los demandantes enviaron a un representante suyo y de Fernando el Ferrí ${ }^{9}$, vecino de San Pedro y San Pablo, para que explicara cuál era el daño que la obra podía causarles y expusiera sus peticiones. Éstas eran que se debían suspender las obras y mandar derruir lo ya hecho; que del agua de la acequia de Aynadamar ${ }^{10}$ se les diese la tercera parte y que, una vez llenos los aljibes y acequias, lo que sobrase fuera a la huerta de Hernando el Ferí. Basaban sus peticiones en el derecho secular ("porque de uno, diez, veinte, treinta, qua-

3. Archivo Diputación Provincial de Granada, libro 7.246, fol. 79r. Para el conocimiento y buen uso de los fondos procedentes de este archivo, ha sido fundamental la ayuda de su directora D. ${ }^{a}$ Pilar Parra Arcas, que aquí quiero destacar y agradecer.

4. Archivo Diputación Provincial de Granada, libro 7.297, fol. 67r.

5. Puede tratarse de Alonso del Castillo.

6. Archivo Municipal de Granada, libro 604, fols. 113v-114v.

7. La obra de A. ORIHUEla Uzal y C. VilcheZ VilcheZ, Aljibes públicos de la Granada islámica, Granada, Ayuntamiento, 1991, proporciona una información muy útil sobre el agua del Albaicín, y concretamente lo que se refiere a sistemas de distribución (acequias y cañerías) y recogida y almacenamiento (aljibes), con un plano general que complementa el texto.

8. Archivo de la Alhambra, L-362, fols. 39v a 50r. Corresponde a una escritura fechada en 1749 relativa al proceso de venta de la Casa del Chapiz.

9. Sic, varias veces a lo largo del pleito.

10. Sobre tal acequia y su aprovechamiento en Granada y el Albaicín, puede verse la obra de M. BARRIOS Aguilera, De la Granada morisca: Acequia y cármenes de Ainadamar (según el apeo de Loaysa), Granada, Ayuntamiento, 1985. 
renta, zinquenta, y zien años asta entonzes, y de tanto tiempo que memoria de hombres no es en contrario") del uso del agua del ramal que iba a las citadas parroquias de Santa Isabel, San Luis y San Blas, de la que siempre se les había dado la tercera parte, y que el sobrante era para la huerta del Ferí.

Oídas ambas partes y examinadas las alegaciones y los antecedentes oportunos, junto a resoluciones anteriores que afectaban al caso, los jueces dictaron sentencia definitiva a favor de los vecinos de las parroquias citadas y de Hernando el Ferí, a quien se le notificó el 5 de marzo de aquel año. Sin embargo, la oposición de Padilla obligó a nuevas intervenciones de unos y de otros, hasta que, finalmente, prevaleció el derecho de los vecinos y se pudo cumplir definitivamente la sentencia judicial, que se firmó con fecha de 24 de mayo de 1531.

Hay aquí dos datos ilustrativos de la importancia del Ferí: uno tener su propio representante en el pleito, y el otro ser poseedor de todos los excedentes de los aljibes del Albaicín ${ }^{11}$, dato que se ratificará en otras ocasiones por declaración del propio Hernando. Así, en 1549, al ser acusado de taponar y desviar la acequia de Aynadamar para provecho propio, se defiende alegando "que yo tengo agua de sobra, porque toda la sobra del agua de los algibes y cauchiles del Albayzin es mia"12, opinión que apoyan los testigos que presenta en su defensa, quienes expresan que "Hernando el Feri tiene mucha agua sobrada porque le pertenesce todo el remaniente de todos los algibes y cauchiles y albercas del Albahezin desta çibdad y asi tienen los testigos por cierto que el dicho Hernando el Feri por ser ombre rico y honrado por lo que dicho es no lo tomo ni lo mando tomar de la acequia la agua" ${ }^{\prime \prime}$.

Sobre la antigüedad de la familia en el Albaicín tenemos noticia a través de un pleito de un hijo suyo, Juan, con los repartidores de la parroquia de San Blas ${ }^{14}$, en relación con el cual se conservan cuatro recibos de farda ${ }^{15}$ en árabe y castellano que se incluirán como apéndice a este trabajo.

El pleito obedecía a que dichos repartidores exigían que pagase allí la farda por pertenecer los bienes de la familia a dicha parroquia, en contra de lo cual Juan el Ferí argumentaba haber nacido en la parroquia de San Pedro y tener a su favor una costumbre instituida a raíz de la toma de la ciudad

11. Para información precisa sobre los aljibes del Albaicín, remito a la citada obra de A. ORIHUELA UZAL y C. VILCHEZ VILCHEZ, Aljibes públicos...

12. Archivo Municipal de Granada, legajo 3.430, p. 20, fol. 2r.

13. Ibídem, fol. $4 \mathrm{r}$.

14. Archivo de la Alhambra, L-188-41, A-86-41.

15. Considero muy ilustrativo y esclarecedor para explicar este término, sus variantes y su aplicación, el trabajo de B. VINCENT, «Las rentas particulares del Reino de Granada en el siglo XVI: fardas, habices, hagüela», Andalucía en la Edad Moderna: Economía y sociedad, Granada, Diputación Provincial, 1985, pp. 96-122. 
por los Reyes Católicos, que presentaba entre las probanzas de los testigos de su parte "16: "Yten si saben [...] ques costunbre usada e guardada en esta çibdad e reyno de Granada despues que los señores Reyes Católicos lo ganaron, que los nuebamente conbertidos deste reyno que estubieren enpadronados en la farda e serviçio de su magestad en una perrochia primeramente e allí lo ubieren pagado, aunque se muden a vivir a otra perrochia del mismo pueblo no se mude el repartimiento a la perrochia donde se muda sino que quede e se le haga en la perrochia donde primeramente se enpadronó".

Y es en este mismo documento, dentro de las probanzas testificales de los repartidores de San Blas, donde se hace alusión a diversas generaciones de la familia ${ }^{17}$ : "Yten si saben que el dicho Hernando el Feri el biejo fue vezino y morador de la dicha perroquia de san Blas dende que fue de hedad de thener casa y sus padres y abuelos bibieron en la dicha perroquia despues questa çibdad se ganó".

El pleito, además de mostrarnos que la práctica totalidad de los testigos que intervienen en las probanzas, por una y otra parte, sólo hablan árabe y tienen necesidad de intérprete ${ }^{18}$, nos da más informaciones relativas a Hernando el Ferí, entre otras la de la fecha de nacimiento y muerte. La segunda podemos deducir que fue la de 1557, habida cuenta que el pleito tuvo lugar en 1561 y en él se dice que Juan, su hijo, se fue a vivir a la casa de su padre cuatro años antes, al ocurrir el fallecimiento de aquél. En cuanto a la de su nacimiento, tenemos la información de uno de los testigos de los repartidores de San Blas, quien indica que "conoçio al dicho Hernando el Feri el viejo que fue vecino e morador en la dicha perroquia de san Blas y en ella lo vido vivir e morar mas tiempo de çinquenta años hasta que fallesçio" "19, es decir, se puede conjeturar como fecha aproximada de nacimiento los últimos años del siglo XV o los primeros años del XVI, aproximadamente.

Hernando estuvo casado con Isabel Abendafir ${ }^{20}$, que aportó al matrimonio una casa, a la que enseguida me referiré, y otros bienes, parte de los cuales nos son conocidos por el padrón de la parroquia de Santa María la Mayor, de $1512^{21}$. Tales bienes eran una almacería en Fornalcayz ${ }^{22}$, emprado-

16. Archivo Municipal de Granada, ibídem, fol. 12r.

17. Ibidem, fols. 16r, 22 r.

18. El año es el de 1561, sólo diez antes de la expulsión.

19. Id., fol. 23 r.

20. Citada también como Abendafra y Abendafride

21. Archivo de la Alhambra L-188-41, A-86-41, fol. 45r.

22. Debe referirse al topónimo árabe Furn al-Qays, que en opinión de L. SECO de LuCENA, La Granada nazarí del siglo XV, Granada, Patronato de la Alhambra, 1975, p. 83, fue un importante horno que dio nombre a una calle, luego llamada de la Gallinería, que accedía a un zoco situado en una zona próxima a la Alcaicería. 
nada en cien pesantes, una viña en Maracena, en sesenta pesantes, otra en Daraxeme ${ }^{23}$, en veinte pesantes, una huerta en el Darro, en doscientos pesantes, y un fadin ${ }^{24}$ en Txey ${ }^{25}$, en doce pesantes y cinco dineros, con un valor total de trescientos noventa y dos pesantes y cinco dineros.

Su padre, del que desconocemos el nombre, debió vivir en la misma zona, como señalan varios testigos que dicen haberlo conocido personalmente: "Y su padre del dicho Hernando el Feri antes que falleçiese lo vido este testigo vivir e morar en la dicha parroquia de san Blas mucho tiempo hasta que fallesçio" ${ }^{26}$, remontándonos, por tanto, a miembros de la familia Ferí presentes en los momentos de la caída de Granada y en años anteriores, lo cual nos lleva a plantear si fueron ellos, el padre o el propio Hernando el viejo, o incluso su suegro, los que compraron la gran casa, conocida luego como Casa del Chapiz, de la que más tarde me ocuparé, o, incluso si tal casa les hubiera sido dada por el poder castellano a cambio de ciertos servicios. De ser así, nos encontraríamos frente a una familia colaboracionista.

Moviéndonos en el terreno de la pura hipótesis, se podría pensar que la familia Ferí accediera a la casa inmediatamente después de la conquista de la ciudad y que tal casa formara parte del patrimonio real nazarí, dado su volumen e importancia. Por esta zona debió estar situada la Dar al Bayḍā que dio nombre a la zona (Raba de Albaida), con lo que se plantea la posibilidad de que se trate de la misma casa $^{27}$. Como simple curiosidad, quiero recordar la

23. Probablemente se trate de Andar al-Šamal, "La Era del Viento Norte”, pago de la Vega granadina, en el término de Peligros. Actualmente lleva el nombre de Andarasemel, habiendo conocido formas intermedias, entre ellas la de Andaraxemel. Cf. L. SECO de LuCENA, Topónimos árabes identificados, Granada, Universidad, 1974, p. 15; M.C. JIMÉNEZ MATA, La Granada islámica, Granada, Universidad-Diputación Provincial, 1990, pp. 128-129.

24. Voz del árabe granadino faddīn, con imala completa, por el árabe clásico faddān, "yunta de bueyes", que designa la extensión de tierra que una yunta de bueyes puede arar en un día. De ahí toma el nombre de obrada o yugada con que se le conoció, cuya medida podría ser equivalente a la de la fanega. En el dialecto hispanoárabe se le identificó con "pago", "predio" "haza" o "finca", sin especificar sus medidas, y con tal sentido aparece en los Libros de Apeo. Este término ha dado lugar a varios topónimos. Cf. A. DÍAZ GARCÍA, «Algunos topónimos árabes granadinos», Revista del Centro de Estudios Históricos de Granada y su Reino, 4 (segunda época) (1990), pp. 117-118 y notas 10 y 11; A. DÍAZ GARCíA y M. BARRIOS AGUILERA, De toponimia granadina, Granada, Universidad-Diputación Provincial, 1991, p. 177 y notas 145 y 146. En ambos casos se hace un detallado estudio de la voz. árabe, de las medidas agrarias a las que corresponde y de los topónimos de ella derivados, recogiendo, al mismo tiempo, la bibliografía más significativa relacionada con todo ello.

25. No identificado.

26. Ibídem.

27. Esta hipótesis, apuntada en su momento por el P. Darío Cabanelas, a quien tengo siempre presente en mi recuerdo, la estudié y desarrollé en mi trabajo «Noticias sobre la Casa del Chapiz», Homenaje al Profesor José María Fórneas Besteiro, Granada, Universidad, 1985, vol. II, pp. 1.139-1.166, al cual remito y en el que recojo los trabajos del P Cabanelas y otros relativos a la casa. 
cita que hace Henríquez de Jorquera ${ }^{28}$ refiriéndose a ella como "la gran casa del Chapiz, para el verano saludable abitación de príncipes".

Frente a esta hipótesis, tenemos datos concretos de que Hernando poseía en 1528 una vivienda en el Albaicín, junto a la Puerta de Guadix, cuyo anterior dueño pudo ser un tal Caçena, que tomaba agua de un ramal de la acequia de Axares. En el documento se especifica que "la posee agora Hernando Feri por su muger" ${ }^{\prime 2}$. Entre esta casa y la citada antes, existen las concordancias de su emplazamiento y la procedencia de su agua, con lo que, de nuevo, se abren interrogantes sobre ella.

Y habiendo llegado a este punto creo oportuno plantear por qué siendo la familia Ferí la que pudo adquirirla y la habitó prácticamente hasta el final, con el paso del tiempo se le haya llamado Casa del Chapiz.

\section{LA CASA DE HERNANDO EL FERÍ: LA CASA DEL CHAPIZ}

Cuando comencé a interesarme por el Chapiz y por la casa de su nombre, me resultó sorprendente que los documentos más antiguos, los citados pleitos de aguas, siempre se referían a la casa y huerta propias de Hernando el Ferí, sin hacer mención alguna del Chapiz. Como todas las noticias que hasta entonces tenía señalaban que la casa había sido de Lorenzo el Chapiz y de su cuñado el Ferí, intenté explicar aquella omisión del Chapiz con diversos argumentos que ahora, disponiendo de nuevos datos, me llevan a otras conclusiones.

Hernando el Ferí fue su único dueño y morador, con datos contrastados, al menos desde 1525, fecha de su pleito con Padilla, hasta 1557, año de su muerte. Ocurrida ésta, pasaron a la casa su hijo Juan y su yerno Lorenzo el Chapiz, quien hasta entonces vivía en el mismo barrio del Albaicín, sin que podamos precisar más que la zona, por lo que se deduce de una visita hecha a las tiendas de la Alcaicería en 1552. En ella aparece Lorenzo el Chapiz como propietario de una de ellas, y al hablar de él se dice: "Lorenço Chapiz que bibe a la collaçion de san Pedro y san Pablo"30.

Por la disposición actual de las viviendas, prácticamente igual a la del siglo XVI, y por lo que se deduce de los distintos documentos, a Juan le debió de corresponder la más pequeña de las dos, que, por otra parte, sería la que estuviera en mejor estado y, muy probablemente, fuera la que habitaba su padre. Al Chapiz le tocó la casa grande y sus anejos ("Lorenço Chapiz

28. Anales de Granada, ed. A. Marín Ocete. Estudio preliminar y nuevos índices por P. Gan Giménez y L. Moreno Garzón, Granada, Universidad, 1987, vol. I, p. 36.

29. Archivo Municipal de Granada, leg. 3.382, p. 11, fol. 5v.

30. Archivo Municipal de Granada, libro 604, fol. 114v. 
esta casado con una hija del dicho Hernando Feri el biejo y por su fin y muerte heredo unas casas suyas prinçipales en la dicha perroquia de san Blas" ${ }^{31}$ ), a los que hizo una serie de obras, como se señala en el mismo documento: "Lorenço el Chapiz hierno del dicho Hernando el Fireh el viejo [...] ha reidificado y continuado la lavor de unas casas principales que fueron del dicho Hernando el Fireh [...] y las mejoras que a hecho en la dicha casa [...] se a edificado con la erencia que ubo del su suegro"32. En años posteriores debió continuar las obras, puesto que en 1568 los repartidores de farda le reclamaron un aumento de treinta pesantes "por la mejoría de la casa en san Blas"33. De acuerdo con estas noticias, cabría pensar que parte de la casa que ha llegado hasta nosotros se edificó, o, al menos, se reformó, entre los citados años de 1557 y 1568.

Desde que se mudó a la casa heredada de su suegro, compartió con su cuñado Juan el Ferí todos los problemas derivados del uso del agua para la huerta común y otros asuntos relacionados con las viviendas. En estos años ya se aprecia que la personalidad del Chapiz es más acusada que la de Juan, seguramente porque su posición social y económica eran más relevantes. Sería entonces cuando comenzara a identificarse el conjunto de las casas y la huerta con Lorenzo más que con Juan, en concreto y, consecuentemente, con la familia Ferí.

Al abandonar Juan su vivienda, por motivos que luego explicaré al ocuparme de este personaje, otro miembro de la familia Ferí, Hernando el joven, se hizo cargo de ella, pero pienso que no llegó a habitarla, como también luego se verá. Por todo ello, cuando en 1572 Felipe II incorporó la casa a la Corona de Castilla, los informes relativos a ella serían que los dueños eran Lorenzo el Chapiz y un cuñado suyo. En las primeras citas que se hacen de la casa se siguen manteniendo los dos nombres, pero, poco a poco, se debió ir perdiendo la memoria del Ferí, hasta quedar identificada definitivamente con el nombre del Chapiz.

Hay, incluso, una referencia de Henríquez de Jorquera, en fecha que se puede situar cerca de $1640^{34}$, cuando al trazar el itinerario que, arrancando

31. Archivo de la Alhambra, L-18-41, A-86-41, fol. 22r. Hay que abandonar, pues, la idea del P. Cabanelas de que la casa situada al sur, la grande, perteneciera a Lorenzo el Chapiz, "padre" (al que supone cuñado del Ferí), de quien la heredó su hijo. Basa esta afirmación en un comentario de Alonso del Castillo referido a una pila de mármol de la que dice que estaba en casa de Lorenzo, hijo, el Chapiz. Cf. D. CABANELAS RODRÍGUEZ, «La casa del Chapiz y la historia de su rescate», Revista del Centro de Estudios Históricos de Granada y su Reino, 1 (segunda época) (1987), pp. 219-220. Su afirmación es lógica según la información de que entonces disponía. Documentos a los que he tenido acceso posteriormente, y que él no utilizó, me han permitido rectificarla.

32. Archivo de la Alhambra, L-188-41, A-86-41, fol. 4v.

33. Archivo de la Alhambra, L-159-33, A-87-33, fol. 4.

34. Así puede deducirse de lo que indican los autores del Estudio Preliminar, p. 26. 
de Plaza Nueva, sube por la calle (sic) del Darro, indica que se llega a la "puerta del Chapiz con

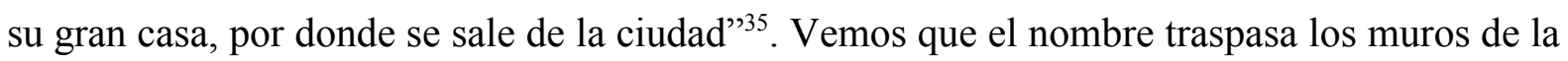
vivienda, sustituyendo, en este caso, al de Puerta de Guadix, que siempre se le había dado.

\section{LOS DESCENDIENTES Y HEREDEROS DE HERNANDO}

Tenemos la certeza de dos hijos: un varón, Juan, de quien, a su vez, se conoce un hijo llamado Miguel, y una hembra, Inés, la mujer de Lorenzo el Chapiz. Hay otro Hernando del que no he podido establecer de manera satisfactoria su parentesco, aunque, indudablemente, es miembro de la familia en grado muy directo. En estos momentos no sé exactamente si fue hijo de Hernando el viejo o de Juan. Más adelante me ocuparé de él.

\section{JUAN EL FERÍ}

Las noticias concretas que tenemos, hasta el momento, de Juan el Ferí es que era mercader y su negocio debía de ser la seda, habida cuenta que en un momento determinado se le llama Maestro de Sedas ${ }^{36}$. Muy probablemente lo centraría en la tienda de la Alcaicería heredada de su padre. A la tienda y a la casa se sumaban, entre sus bienes, la herencia procedente de su madre, de la que sólo se conservaba la viña de Maracena ${ }^{37}$, y lo que aportara al matrimonio su mujer, María Marçe, hija de Francisco Marçe y de María Harrifa, su segunda mujer ${ }^{38}$. Tenemos noticia de un hijo suyo, Miguel, nacido en 1546, que aparece repetidamente en el citado pleito con los repartidores de San Blas y del que se nos dice que vivía con su padre por su corta edad, 15 años, ser soltero y no tener hacienda propia.

Como ya hemos visto, como heredero de Hernando el viejo ocupó la vivienda que antes había sido de su padre y en ella estuvo, al menos, desde 1557 a 1569, años en los que figura en diversos pleitos de aguas junto a su cuñado Lorenzo el Chapiz Al desaparecer Hernando el Ferí el viejo fueron ellos dos los que se ocuparon de los problemas familiares. Sabemos que vivían en casas contiguas y que compartían la huerta y el agua que antes habían sido de Hernando, con motivo de una petición que ambos hicieron para abrir la calle y encañar el agua de la vivienda: “[...] y la llevan por una

35. Vol. I, p. 31 .

36. Archivo Diputación Provincial de Granada, libro 7.297, fol. 67r.

37. Archivo de la Alhambra, L-188-41, A-86-41, fols. 42r-42v.

38. Archivo de la Alhambra, L-188-41, A-86-41, fol. 32r. 
reguera a regar una huerta de Hernando el Feri cuyo heredero es el dicho Lorenço Jabiz e un fijo del dicho Feri agora estos de concordia quieren llevar el dicho remaniente limpio e incorporallo en unos caños que van a sus casas que estan juntas [...]"39.

Ambos, Lorenzo y Juan, debían tener buena posición económica y, sin duda, serían los más acaudalados de la parroquia de $\operatorname{San} \mathrm{Blas}^{40}$ a la que pertenecían sus casas, como atestiguan los repartidores de aquélla: "Yten si saben que la dicha perroquia de san Blas es pobre y si de ella se sacase al dicho Miguel el Feri y Juan el Feri, su padre, y Lorenço Chapiz, que son personas ricas, destruie a los pobres y biudas de la dicha perroquia"41.

El final de Juan el Ferí es confuso. Es posible que participara en los acontecimientos previos al levantamiento morisco o, al menos, fue acusado de ello, puesto que en 1569 se le confiscaron la tienda de la Alcaicería y sus otros bienes: "Y habiendo acaecido despues el levantamiento de los moriscos deste Reyno por el año pasado de 1569 y comprehendidos en el dicho Juan el Feri, le fueron confiscados sus vienes y entre ellos la expresada tienda [...] se mando por dicho Consejo [de Población] que [...] S.M. se quedase con las dichas posesiones"42.

En esta confiscación hay algo extraño. Se supone que entre los bienes incautados debía estar la casa del Albaicín en la que vivía, la llamada del Chapiz, y sin embargo, un año después, en 1570, aparece otro Ferí, Hernando el joven, como propietario de ella, sin olvidar que Lorenzo el Chapiz también estaba allí. Resulta difícil explicar hasta qué punto fue personal la acusación que sólo le afectó a él, dejando al margen a sus familiares.

\section{LORENZO EL CHAPIZ}

De Lorenzo el Chapiz me ocupé con cierta extensión en otro momento ${ }^{43}$, por lo que limitaré las noticias referidas a él a los rasgos imprescindibles, además de incorporar algún dato nuevo.

39. Archivo Municipal de Granada, legajo 3.425, p. 20, fol. 6v.

40. Esta parroquia, citada varias veces a lo largo de este trabajo, acabó siendo integrada dentro de la del Salvador. HENRÍQUEZ de JORQUERA, Anales, vol. I, p. 214, dice que, junto con ella, se integraron las de San Martín y San Sebastián, en tanto M. GÓMEZ-MORENO, Guía de Granada, Granada, 1892 (ed. facsímil, Granada, 1982) p. 482, dice que fueron las de San Blas y Santa Inés las anexadas, dando la fecha de 1508, año que no concuerda con los datos aquí analizados, en los que vemos a los repartidores de esta parroquia pleiteando en 1561 .

41. Archivo de la Alhambra, L-188-41, A-86-41, fol. 22v.

42. Archivo Diputación provincial de Granada, libro 7.297 (Libro de censos del Real Hospicio), fol. 637v.

43. Véase mi trabajo «Lorenzo el Chapiz y el "Negocio General” de 1559», Qurtuba, 1, 1996, pp. 11-38. 
Su nombre era Lorenzo Hernández el Chapiz, a veces citado como Jabiz, Japiz, o Apiz. Por el testamento de su abuelo materno ${ }^{44}$ sabemos que fue hijo de Martín López el Chapiz y de Isabel Jarrelia, y nieto, por parte materna, de Pedro el Jerrí y Elvira Salenia, cristianos nuevos todos ellos. Se da la circunstancia de que los abuelos sobrevivieron a los padres, ya que en 1549, fecha en que se redacta el testamento de Pedro el Jerrí, así se indica. Tuvo un hermano llamado Álvaro, menor que él, citado como alamín ${ }^{45}$. De sus ascendientes paternos no tenemos datos.

Como ya he señalado, estuvo casado con Inés Ferí, hija de Hernando el Ferí el viejo, de cuyo matrimonio sólo queda constancia de un hijo, Alonso, bautizado en la iglesia de San Pedro en agosto de $1561^{46}$. A esta parroquia había pertenecido siempre la familia Chapiz y de ella fue repartidor Lorenzo ${ }^{47}$.

Fue hombre acaudalado, propietario de tierras en diversos lugares del territorio de Granada, con Almuñécar como zona en donde se concentró la mayor parte de sus bienes, a la vista de la relación de tierras de moriscos cuyo remate se hizo a partir de $1575^{48}$. En él se recogen 89 hazas de caña de azúcar con una superficie de 416 marjales y 56 estadales, lo que le convertía en el mayor terrateniente morisco del lugar. Además de las hazas y unos morales que poseía allí, se liquidaron, también como antiguos bienes de Lorenzo el Chapiz, un molino, en estado ruinoso, y un ingenio de azúcar.

Fuera del término de Almuñécar, el Chapiz poseía desde 1562, a título de censo perpetuo por valor de 50 ducados anuales, junto a otros cuatro individuos y dentro del término municipal de Santa Fe, tierras de riego en el mismo pueblo de Santa Fe, el Jau, el Salado y el Juncal ${ }^{49}$.

44. Doc. 188 del Archivo de Protocolos de Granada, Sección de Granada, Escribanía de Diego Sánchez. Agradezco muy sinceramente a D. ${ }^{\text {a }}$ Margarita Birriel Salcedo el haberme proporcionado copia de este documento.

45. Archivo Municipal de Granada, libro 604, fol. 63r.

46. Son datos tomados del libro de bautismos conservado en esta parroquia, Baptismos de la Yglesia parrochial de S. Pedro y San Pablo. Año de 1552 y asta 1593. La inscripción aparece en el fol. 41r.

47. Archivo de la Alhambra, L-188-41, A-86-41, fol. 4v

48. Abecedario de remates de Motril, Salobreña y Almuñécar, actualmente perteneciente a los fondos del Archivo Histórico Provincial de Granada, 5/a-3/117b. Margarita Birriel ha analizado a fondo este documento, como se recoge en varios trabajos suyos. En ellos y en informaciones personales de la autora, además de mi consulta directa del texto del Abecedario, baso los datos que ofrezco. Los trabajos de M. BIRRIEL a que me refiero son «Ventas de bienes confiscados a moriscos en la tierra de Almuñécar», Chronica Nova, 16, 1988, pp. 39-53; La tierra de Almuñécar en tiempos de Felipe II, Granada, Universidad-Ayuntamiento de Almuñécar, 1989 y «Nuevos datos sobre el patrimonio confiscado a los moriscos: la costa de Granada», Chronica Nova, 21, 1993, pp. 31-61.

49. Archivo de la Alhambra, A-109-47, L-87-47. 
Del mismo modo, figura entre los propietarios de tierras en el pago de Tafiar Zufla ${ }^{50} \mathrm{y}$ de un cortijo llamado Alhondiguilla Alta, entre Illora y Moclín, de doscientas cincuenta fanegas de tierra, con cinco casas dentro de él, que compartía con Hernán López el Ferí el joven ${ }^{51}$.

En la ciudad de Granada poseía una tienda en la Alcaicería ${ }^{52}$, que gestionaba directamente, y otra de la que consta que en 1552 tenía alquilada a Ramiro de Palencia, por una renta anual de veinte ducados ${ }^{53}$. Finalmente, en la relación de sus bienes habría que incluir un molino de pan en el Albaicín ${ }^{54}$, la vivienda que ocupara en los años anteriores a 1557 y la gran casa que, a partir de ese año, recibió de la familia Ferí, que luego tomaría su nombre (el del Chapiz), de la que ya he hablado en este trabajo y de la que me he ocupado más ampliamente en otras ocasiones ${ }^{55}$.

La procedencia de todo aquel capital debió de ser variada. Por el testamento de su abuelo materno sabemos que fue, junto a su hermano Alvaro, heredero universal de aquél. No hay detalles acerca de los bienes recibidos ${ }^{56}$, que el testador dice que eran abundantes. Otra procedencia sería la herencia paterna, de algunas de cuyas posesiones nos ha quedado noticia, como es el caso de dos viviendas situadas en el Albaicín, cerca de la Puerta de Guadix, citadas una como casa de Vitoria y la otra casa de Rebolledo ${ }^{57}$, nombres que pueden hacer alusión a anteriores dueños, y de una tienda en la Alcaicería ${ }^{58}$. Finalmente, Lorenzo el Chapiz poseía como tercera vía de riqueza la de sus propios negocios. Aparece citado siempre como mercader.

$\mathrm{Su}$ presencia en la vida política granadina tuvo un protagonismo excepcional por su participación en el "negocio general", del que luego hablaré. Por la importancia que su figura adquiere en este caso y por un documento redactado en $1571^{59}$, en el que aparece pleiteando por sus derechos, podría dar la impresión de sentirse seguro, moviéndose con libertad por Granada al

50. M. BARrios AguilerA, «Tafiar Zufla, un pago morisco del ruedo de la ciudad de Granada», Moriscos y Repoblación; En las postrimerías de la Granada islámica, Granada, 1993, p. 194.

51. Archivo Real Chancillería de Granada, legajo 4.341, p. 11.

52. Archivo de la Alhambra, A-89-11, L-80-11, fol. 24.

53. Archivo Municipal de Granada, libro 604, fol. 114v.

54. Archivo Municipal de Granada, leg. 3.490, p. 1.

55. En los citados trabajos «Lorenzo el Chapiz y el Negocio General...» y «Noticias sobre la Casa del Chapiz»...

56. Álvaro heredó, entre otras cosas, una tienda que poseía su abuelo en la Alcaicería. Cf. Archivo Municipal de Granada, libro 604, fol. 63r.

57. Archivo Municipal de Granada, leg. 3.382, p. 11, fols. 7r y 7v. La cita corresponde al año 1528 .

58. Archivo Municipal de Granada, libro 604, fol. 74v.

59. Archivo de la Alhambra, L-159-40. 
margen de los acontecimientos que se estaban viviendo, pero, como en el caso de Juan, y más tarde en el de Hernando el Ferí el joven, alguna acusación grave pesaría sobre él porque acabó encarcelado en la Chancillería granadina, "presso por el levantamiento deste reyno", en texto fechado en $1572^{60}$. Se podía sospechar algo de ello, puesto que cuando se revisan las escrituras de la Casa del Chapiz, se repite siempre que pasaron a la corona en virtud de la Carta de Incorporación de Felipe II de comienzos de 1571, aunque con la contradicción de que la Carta se firmó al empezar el año y el pleito del Chapiz es del mes de junio. Es decir, el Chapiz seguía viviendo en una casa que, oficialmente, le había sido quitada varios meses antes.

De lo que le ocurriera a él o a su familia nada sabemos, por el momento. En 1582 apareció en Pastrana un Felipe Hernández el Chapiz, hijo de Álvaro Hernández el Chapiz, "vecino de Granada [...] seyse que fue de la parroquia de san Pedro y san Pablo. Vino por orden de don Pedro de Castro presidente de la Chancillería, y dijo con su voluntad. Y truxo consigo a su madre y un hermano y un criado"61. Entra dentro de lo posible que se tratara de un sobrino de Lorenzo, hijo de su hermano menor, ya mencionado.

Pasados los años, concretamente en 1609, aparece otro personaje con el nombre de Chapiz situado en Toulouse, en donde, junto a su suegro, daba alojamiento a moriscos que pasaban por allí, de camino hacia otros lugares, e incluso se encargaba de guardar el dinero que le enviaban algunos moriscos desde España y que, en su momento, irían a buscar allí6 ${ }^{6}$. Por las fechas y por el hecho de figurar su suegro con él, no parece probable que fuera Lorenzo; no sé si aventurar que se tratara de su hijo Alonso o de un descendiente. En cualquier caso, no hay que olvidar que hubo varios individuos que llevaron el nombre de Chapiz, sin tener ninguna relación con el que nos interesa.

\section{EL ENIGMÁTICO "NEGOCIO GENERAL”}

Es, sin duda, el acontecimiento que marca la personalidad de Lorenzo el Chapiz y le hace aparecer como figura de relieve en el mundo morisco granadino. Debemos su conocimiento a un pleito mantenido entre don

60. Archivo Real Chancillería de Granada, legajo 4.341, fol. 11.

61. Archivo Zubalburu, M-16-411, cédula de 20/11/1582. En éste, como en otros casos a lo largo de este trabajo, debo la noticia a la amabilidad del Dr. Bernard Vincent.

62. La referencia corresponde a un documento del Archivo General de Simancas, Estado, leg. 2.639, fols. 9-11, recogido por H. BOUZINEB y G. WIEGERS, «Tetuán y la expulsión de los moriscos», Tițwān jilāl al-qarnayn 16 wa 17, Tetuán, 1996, pp. 92-95. 
Hernando de Mendoza de Fez Muley ${ }^{63}$ y Lorenzo el Chapiz ${ }^{64}$, en el que aquél reclamaba a éste una cantidad de dinero por su participación en dicho "negocio", que había tenido lugar en $1559^{65}$. En aquel proceso iban a tomar parte destacados personajes de la Granada del siglo XVI y miembros de las principales familias moriscas granadinas, con la especial participación de Lorenzo el Chapiz, que aparece como figura clave, coordinando un problema de gran envergadura que afectó a todos los moriscos del reino de Granada y en el que, además, se vieron involucrados la Corona y la Inquisición, que, en última instancia, era la que estaba detrás de todo aquello.

Parece que el motivo del "negocio" no era más que un nuevo intento, por parte de los moriscos, de una recaudación extraordinaria destinada a mantener una convivencia aceptable con el poder castellano y con la Inquisición. En 1526, precisamente el mismo año en que la Inquisición se instaló en la ciudad, ya se había pactado con Carlos V el pago de una contribución especial de 90.000 ducados en seis años, a cambio de que se suspendieran todas las medidas que contra ellos se venían tomando. Para mantener aquella relativa tranquilidad, los moriscos renovaron sus propuestas a la Corona y a la Inquisición en 1543, 1555 y 1558, pero sus intentos parece que no prosperaron. También en 1556 don Hernando de Mendoza de Fez Muley había viajado a las Alpujarras llevado por el mismo "negocio" que, poco después, iba a ser la causa de su pleito con el Chapiz.

En el desarrollo de estas negociaciones hay un detalle que, tal vez, debería ser tenido en cuenta: 1556 fue el año en que Felipe II subió al trono, y cabe la posibilidad de que analizara los pactos de su padre con los moriscos y los considerara, cuando menos, dignos de ser revisados para revocarlos o continuarlos con modificaciones. Es, precisamente, el año en que Fez Muley fue a la Alpujarra a tratar el "negocio general".

No tenemos datos concretos del desenlace del "negocio", aunque sospecho que no se llegara a ningún acuerdo definitivo. Creo que, dado que en varios momentos del pleito entre Fez Muley y el Chapiz se dice explícitamente que el negocio dependía del Consejo de la Inquisición, posiblemente un análisis de la documentación de este Tribunal, correspondiente a estos años y a los posteriores, podría darnos alguna información fiable.

63. Sobre este personaje y, fundamentalmente, sobre su familia, encontramos datos recientes e interesantes en el trabajo de M. ${ }^{a}$ J. RUBIERA MATA, «La familia morisca de los Muley-Fez, príncipes meriníes e infantes de Granada», Sharq al-Andalus, 13, 1996, pp. 159-167.

64. Archivo de la Alhambra, L-80-11, folios 3-62.

65. Vuelvo a remitir a mi trabajo «Lorenzo el Chapiz y el "negocio general"»..., en donde pormenorizo los detalles del mismo. 


\section{HERNANDO EL FERÍ, "EL JOVEN"}

Siempre que se ha hecho alusión a la Casa del Chapiz se ha dicho que perteneció a Lorenzo el Chapiz y a su cuñado Hernán López el Ferí. Según ello, este Hernando sería hermano de Juan e hijo de Hernando el viejo, pero también cabe la posibilidad de que Hernando el joven fuera hijo de Juan, con lo que resultaría ser sobrino de Lorenzo el Chapiz.

En favor de este argumento ${ }^{66}$ encontramos una cita en el pleito que Juan tuvo con los repartidores de San Blas, en el que, en un momento concreto, se señala: “[...] Otro si dezimos que siendo como es Juan el Fireh, mercader, padre del dicho Miguel y Hernando Fireh, su hijo veçinos de la dicha perroquia de san Blas [...J"67. Sin embargo, en el mismo documento encontramos dos datos que complican este parentesco. Por una parte, aparece la queja de los repartidores de San Blas hacia los de San Pedro "por haberles sacado y tomado las pechas de los dichos Hernando y Juan Fireh" 68 , lo que permite suponer que el tal Hernando era hombre de una edad e independencia económica que lo hacen muy próximo cronológicamente a Juan, es decir, podría ser su hermano, o, de no ser así, la diferencia con el otro hijo, Miguel, era muy notable. El otro dato aparece unas líneas más tarde cuando se señala "[...] que los caudales y haziendas [...] del dicho Juan Fireh y de Fracisco Marçe, suegro de los dichos Hernando y Juan"69, lo que los convierte en hermanos.

Algo más contribuye a la idea de que se tratase de persona de cierta edad. Por una parte, que en 1557 tuviera licencia para llevar $\operatorname{armas}^{70} \mathrm{y}$, además, que en 1561 aparezca como propietario de una almazara y una casa en la colación de San Pedro, que debía ser su vivienda en esos años, por lo que se deduce de una petición que hizo a los jueces de aguas: "En Granada a nuebe dias del mes de julio de 1561 años Hernando Feri vecino desta çibdad dio una petizion ante los señores juezes de las aguas por la que dijo que el tiene una casa principal y una almazara en la collacion de san Pedro y san Pablo e que ambas dos tienen agua con salida de la acequia de Axares e que porque al presente no tiene necesidad del agua de la dicha almazara la quie-

66. B. Vincent, en nota personal, refiriéndose a la autorización de Hernando el Ferí para llevar armas, en 1557, citada infra en nota 70, señala: "hijo de Juan, nieto de Hernando".

67. Archivo de la Alhambra, L-188-41, A-86-41, fol. 4r.

68. Ibidem.

69. Ibídem, fol. $4 \mathrm{v}$.

70. Archivo General de Simancas, Cámara de Castilla, cédula 256, fol. 176v. Debo esta noticia al profesor Bernard Vincent. En el mismo documento, fol. 142v., con fecha de 1550, también con licencia para portar armas figura Álvaro de Fez Muley, miembro de una destacada familia morisca granadina, sobre la que

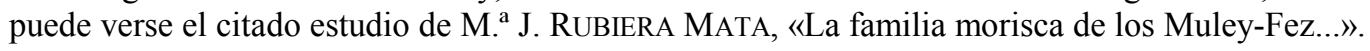


re juntar con el agua de la casa principal e quitarla de la dicha almazara. [...] Loaysa, administrador de las aguas, lo vido e dio su parescer que se le podia dar lizenzia para lo que pedia $[\ldots]^{\prime, 71}$.

Años más tarde, en 1569, y citado como mercader, figura cobrando una deuda a otro mercader morisco ${ }^{72}$ y ese mismo año debió de tomar la propiedad de la Casa del Chapiz, en donde antes había vivido Juan, quien había sido despojado de sus bienes, aunque quizá no llegara nunca a habitarla, si bien se preocupara de lo que a ella correspondía. Llego a esta conclusión a la vista del contenido de un pleito de 1570, en el que algunos vecinos del Albaicín, usuarios de la acequia de Aynadamar, le acusan de haber forzado el repartimiento de la Puerta de Fajalauza.

Este es el expresivo relato de los hechos: "En la ciudad de Granada a beynte y uno de julio de mill e quinientos e setenta años ante el muy magnifico señor el dolor Merino de Espinosa alcalde mayor de Granada [...] Alonso de Saldaña teniente administrador presento por testigo a Beatriz Hernandez [...] que siendo preguntada dixo que esta testigo vive a la Puerta de Faxalauza [...] a donde esta el repartimiento del agua que ba a san Luis y [...] acequia de Aynadamar [...] Dicha agua pertenece a esta ciudad [...] edificios publicos del Albaicin y Alacaba y que el biernes pasado diez y seis dias deste mes estando la testigo en su casa, a las diez del dia poco mas o menos, llego a ella el dicho Hernando el Feri y con el dos ombres [...] y el dicho Feri le dijo a esta testigo que le dejare entrar por su casa para entrar en el repartimiento para ber por donde iba el agua, y esta testigo le dijo que no era aquella la puerta por donde abia de entrar. Y ansi se fueron y llamaron a la otra puerta y no estaba alli nadie. Y en presencia desta testigo el dicho Hernando el Feri dijo a los que yban con el: 'Pues bemos benido no bamos sin agua. Que abra esa puerta y entra dentro y atapa ese tomadero'. Y uno de los tres ombres ${ }^{73}$ que yban con el, que era cristiano biejo, que cree que si lo be lo conocera, con el mocho de la azada quebro la puerta del repartimiento y la hizo pedaços y entro dentro del dicho repartimiento el dicho ombre y metio munchos tascos y espuertas de piedra y quito la dicha agua que benia a la ciudad encaminada y la echo al ramal de san Luis [...]"74.

De la acusación se defendió el Ferí alegando que en la fecha citada él no vivía en la casa, para lo que adjuntaba la declaración pertinente en la que mostraba que la tenía arrendada al doctor Navarrete. El plazo que se estable-

71. Archivo Municipal de Granada, legajo 3.486, p. 12, fol. 47r.

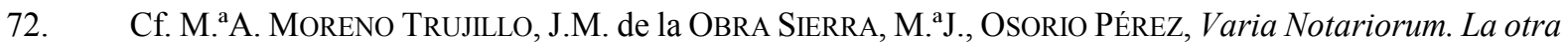
Historia de los granadinos del siglo XVI, Granada, Ilustre Colegio Notarial, 1993, pp. 287-289.

73. Antes había dicho que eran dos.

74. Archivo Municipal de Granada, legajo 3.442, p. 18. 
cía como arrendamiento era de tres años y la fecha en que se firmó el contrato la de 4 de febrero de 1570. Los términos en los que se refiere a ella demuestran ser la misma casa de la que hablamos: "Sepan quantos esta carta de arrendamiento bieren como yo Hernan Lopez el Feri bezino desta ciudad de Granada otorgo y conozco que arriendo y doy arrenta al Ilustre Doctor Nabarrete, del Consejo de Su Majestad, su Oidor en la Real Chancilleria de Granada, de unas casas principales y huerta con otra casa accesoria que yo tengo junto a la que esta juntamente en ella incorporada y se manda por una puerta de la dicha casa las cuales estan en esta ciudad de Granada, en la collacion del señor san Blas, que an por linderos casas de Lorenço Hernandez el Chapiz de la una parte y de la otra la calle real $[\ldots]^{75}$.

Siguiendo con el mismo texto, al especificar las condiciones de pago y los plazos, encontramos una noticia sorprendente: "[...] la tercia parte, que son diez y ocho ducados por el mes de abril deste presente año de la fecha desta carta y la otra tercia parte por el mes de agosto siguiente y la otra tercia parte para nabidad luego siguiente que son quando Su Magestad me paga mis tercios de mi salario"76. Es posible que este salario procediera de las fardas, de cuyos fondos se destinaba un dinero para pagar los servicios de moriscos notables, entre los que figuraban los miembros de las más destacadas familias: León, Zegrí, Muley Venegas, Belbis... ${ }^{77}$. Podría servir de muestra fehaciente de su posición en la sociedad morisca.

Este escrito tiene varios hechos destacables. El principal, desde luego, es el ya señalado razonamiento del Ferí de probar con esta carta de arrendamiento, a los litigantes de la acequia de Aynadamar, que en la fecha en que se le acusa de haber roto el tomadero de agua él no vivía allí, sino el doctor Navarrete. Además, en las probanzas de los testigos que presenta hay una en la que hace constar que no tiene casa alguna en el Albaicín, lo que podría indicar que había dejado la casa que tenía en la colación de San Pedro en 1561. Con ello se nos plantea la duda de dónde podría vivir, pero nos da la seguridad de que no era en la casa de Juan.

Y más datos para la reflexión. Si percibía salario real en 1570 y, además, arrendaba su casa por plazo de tres años, ¿cómo se puede explicar que en febrero de 1572, cuando la Corona toma posesión del cortijo de la Alhondiguilla Alta, que compartía con Lorenzo el Chapiz, se diga de él que fue "lleuado fuera del reino [...] por el levantamiento deste reyno"? ${ }^{78}$.

75. Archivo Municipal de Granada, legajo 3.442, p. 18, fol. 11r.

76. Ibidem.

77. Cf. B. VINCENT, «Las rentas particulares del Reino de Granada», p. 105.

78. Archivo Real Chancillería de Granada, leg. 4.341, fol. 11. 
Aún habrá noticia suya posterior en el tiempo. Con fecha de 12 de octubre de 1578 aparece un Diego de Mendoza relacionado con Hernando por una cantidad de 720 reales y 20 maravedís "que le devía de mercaderias que saco de su tierra de Granada"79.

Como en los casos de Juan y de Lorenzo el Chapiz, desconozco su destino tras la probable salida de Granada.

\section{CONSIDERACIONES FINALES}

Parece que, por lo visto en los documentos que anteceden, la familia Ferí debe integrarse dentro de la oligarquía morisca que en el siglo XVI había en el reino de Granada. Poseedores todos sus miembros de tierras en la provincia, tiendas en la Alcaicería, y casas y almazaras en el Albaicín, gozaron de una solvencia económica y una posición social suficientemente contrastadas en los diversos documentos que hemos analizado. De manera general, y de modo especial los dos personajes que llevaron el nombre de Hernando y su pariente político Lorenzo el Chapiz, merecerían incorporarse al grupo de familias dominantes en la Granada morisca, del que formaban parte descendientes de los principales linajes de los últimos años del reino nazarí y otros poseedores de un buen patrimonio económico.

A título de ejemplo comparativo, y siempre referido a familias notables ${ }^{80}$, sabemos que algún miembro de la familia Hermez, una de las más poderosas de este momento, emparentada con los Vanegas y los Mendoza, poseía en 1571 tres casas, una tienda y otra amplia vivienda en San Salvador y que Pedro López Çaybona era dueño de tres casas, dos casillas, una fonda y un molino.

La política de atración de los Reyes Católicos hacia aquellas familias creó unos vínculos que suponían darles el nombre de colaboracionistas, al tiempo que se sentían, en la mayor parte de los casos, intermediarios entre el poder real y la comunidad morisca. Mantener ese equilibrio a satisfacción de todos era difícil y creó sucesivos problemas que se agravaron al producirse la sublevación de los moriscos, en la que algunos miembros de aquella nobleza local tomaron, no sólo partido, sino incluso parte activa en la lucha a favor de Castilla ${ }^{81}$, mientras que otros permanecieron más cerca de sus raí-

79. Archivo General de Simancas, Cámara de Castilla, leg. 2.182. Nuevamente debo agradecer su conocimiento al Dr. B. Vincent.

80. Son datos proporcionados por B. VINCENT, «El Albaicín de Granada en el siglo XVI (1527-1587)», Andalucía en la Edad Moderna..., pp. 140-141.

81. Cf., entre otros, A. Domínguez Ortiz y B. Vincent, Historia de los moriscos, Madrid, Alianza Editorial, 1993, pp. 152 y ss. 
ces, de los cristianos nuevos, luchando siempre por su causa ante la corte cristiana, entre ellos la familia Fez Muley ${ }^{82}$. En uno y otro caso, parece claro que, sobre todo en momentos de calma, su posición, al menos social, estaba más cerca del poder castellano que de la masa popular morisca y sus problemas.

También en lo económico las posiciones de uno y otro grupo se veían alteradas en función de su relación con el poder castellano: mientras el morisco del pueblo debía pagar la farda, los miembros de la elite no sólo estaban exentos de tal pago sino que recibían gratificaciones por dicho impuesto ${ }^{83}$, como en otro momento señalaba.

El final de aquella minoría, o, al menos, de buena parte de ella, fue, como el del resto de la sociedad morisca granadina, la cárcel o el exilio, en ambos casos con pérdida de todos sus bienes.

\section{APÉNDICE DOCUMENTAL}

Los cuatro recibos de farda que incluyo están contenidos en el documento L-188-41, A-86-41 del Archivo de la Alhambra, formando parte del pleito mantenido entre los repartidores de la parroquia de San Blas y Juan el Ferí, del que ya he hablado antes.

Como suele ser habitual, las cantidades de dinero y el año se expresan en cifras rumíes, que aparecen, en el primer caso, en el margen superior del recibo, y en el segundo al final del texto árabe, tras la voz 'am.

Por estar cosidos al resto de folios del expediente, el margen izquierdo se lee con mucha dificultad, y en algunos casos no puede verse nada. Cuando he tenido elementos suficientes en los que basarme y la lógica lo ha permitido, he podido reproducir el término que estaba semioculto. Con las palabras árabes no ha habido ninguna dificultad, en cambio ha sido más problemático el caso de las cifras rumíes ${ }^{84}$ referidas al año, especialmente en el primero y en el tercero de los recibos.

82. B. VINCENT, Minorías y marginados en la España del siglo XVI, Granada, Diputación Provincial, 1987, pp. 21-22; M.J. RUBIERA MATA, «La familia morisca de los Muley-Fez...», pp. 160, 166.

83. B. VINCENT, «Los elementos de solidaridad en el seno de la minoría morisca (siglo XVI)», Andalucía en la Edad Moderna..., pp. 206, 207.

84. Sobre el origen, identificación y, en general, datos sobre estas cifras, puede servir como bibliografía básica y asequible A. GONZÁleZ PALENCIA, Los mozárabes de Toledo de los siglos XII y XIII, vol. IV, Madrid, 1930, especialmente p. 48; J.A. SÁNCHEZ PÉREZ «Sobre las cifras rumíes», Al-Andalus, III, 1935, pp. 97-125; A. LABARTA y C. BARCELÓ, Números y cifras en los documentos arábigohispanos, Córdoba, Universidad, 1988; J. MARTínEZ RUIZ, «Catorce recibos bilingües (árabe-español) de impuesto de farda en el Archivo de la Alhambra (1511-1564)» Homenaje al Prof. Jacinto Bosch Vilá, Granada, Universidad, 1991, vol. I, pp. 599-618. 
Las equivalencias monetarias que figuran son: un pesante igual a un metical (recibos I y III) o a un dinar de plata (recibos II y IV); un dinero igual a un dirhem (recibos I, II y III).

Quiero recordar que un pesante equivalía a diez dineros y un dinero eran tres maravedís ${ }^{85}$. Su correspondencia en moneda árabe sería la de un dinar de plata igual a un metical e igual a diez dirhemes.

Su análisis lingüístico nos muestra la transcripción por $\check{s} \bar{I} m$ de la $s$ española en san y santa. Parece característica del hispanoárabe considerar próximas ambas pronunciaciones ${ }^{86}$.

En los nombres Pedro y Pablo (II, III), la $p$ se transcribe con el ba simple, sin la šadda de duplicación que en la literatura aljamiado-morisca servía para representar la letra $p$. En el primero de los nombres la $d$ se transcribe por su equivalente árabe $\underline{d} a t^{87}$.

Se emplea el $\hat{y} \bar{m} m$ para transcribir la $j$ de Juan (I, II, III) y la $s$ de Isabel (IV). El primer caso la equivalencia es habitual ${ }^{88}$, mientras en el segundo representa un cambio de sibilantes, ya atestiguado en el mozárabe, por $c$ ( $t s), \mathrm{y} z(d z)^{89}$.

En los numerales se utiliza el plural ùna en las decenas, así como los puntos de la $t \bar{a}$ marbüt $a$ en las unidades, excepto en el caso de 'ašara (IV).

Omite los puntos de esta letra en fiddiyya y fidda (II, IV), así como en Mariya y farda (IV). Esta omisión refleja un rasgo conocido del árabe andalusí de uniformización del femenino en un morfema fijo, el timbre /-a-/, dejando como opcionales las terminaciones propias de este género (tā marbūt.a, alif maqș ūra, alif de prolongación con hamza $)^{90}$.

En ningún caso se emplea el tašdìd.

85. I. Álvarez de Cienfuegos, «La hacienda de los nașríes granadinos», Miscelánea de Estudios Árabes y Hebraicos, VIII, 1959, p. 122, añade a estas equivalencias la de un dinero igual a ocho fuluzes. Por su parte A. LABARTA y C. BARCELÓ, op. cit., p. 13 dan a un dinero el valor de doce cornados.

86. J. MARTÍNEZ RUIZ, «Catorce recibos...», p. 602.

87. Ibídem.

88. A. STEIGER, Contribución a la fonética del hispano-árabe y de los arabismos en el ibero-románico y el siciliano, Madrid, 1932, p. 181 y ss.

89. J. MARTÍNEZ RUIZ, «Lenguas de contacto: Hispanoárabe granadino y castellano de repoblación», Actas del I Congreso Internacional de Historia de la Lengua Española, (Cáceres 30 de marzo-4 de abril de 1987), pp. 151-152. El autor incluye varias citas del nombre de Isabel, siempre transcrito con la misma grafía: I $\hat{y} a b \hat{l}$.

90. M.J. ViguERA, «Sobre manuscritos mudéjares: Documentos fechados en Aragón entre los siglos $6 .^{\circ}-10 .^{\circ}$ de la Hégira (XII-XVI d. J.C.)», Manuscrits arabes en Occident musulman. États des collections et perspectives de la recherche, Casablanca, F.R.A.A.S.-Wallada, 1990, p. 21. 
I (fol. 36r.)

a) Texto árabe:

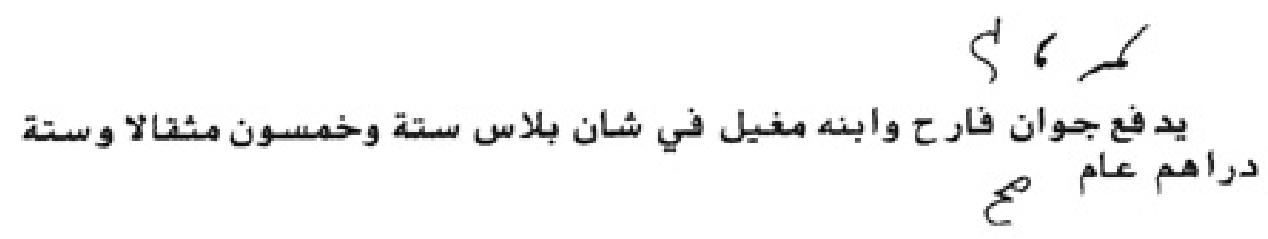

b) Texto castellano:

"Juan Lopez Fireh y su hijo Miguel por la herencia de Isabel Abendafra paguen en san Blas çinquenta y seis pesantes y seis dineros de los serviçios deste año de MD y sesenta".

c) Traducción:

"Pague Juan Fārih y su hijo Miguel en san Blas cincuenta y siete meticales y siete dirhemes. Año [15]60".

d) Cifras rumíes:

Margen superior:

$$
S=\text { cincuenta } \quad \quad 6=\operatorname{seis}(\text { pesantes }) \quad \text { seis(dineros) }
$$

Fecha:

$[\ldots]\left[\right.$ (legible) $\quad \sum=$ sesenta

II (fol. 37r.)

a) Texto árabe

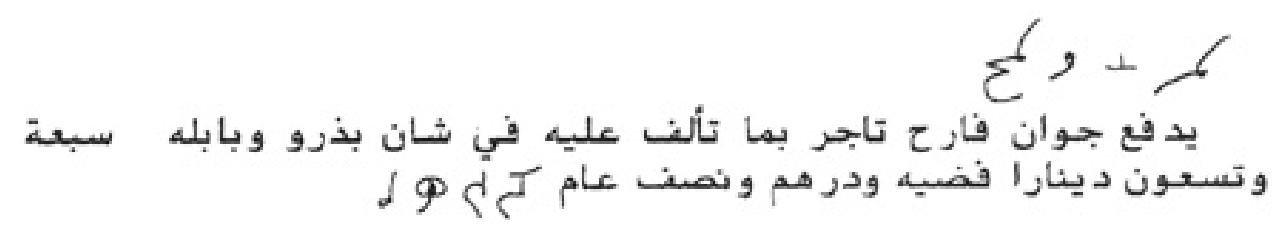

b) Texto castellano:

"Juan el Fireh y su hijo Miguel paguen en san Pedro y san Pablo noventa y siete pesantes y un dinero y medio de los serviçios deste año de MDLVIII".

c) Traducción:

"Pague Juan Fārih, mercader, por lo que le corresponde en san Pedro y [san] Pablo noventa y siete dinares de plata y un dirhem y medio. Año 1558".

d) Cifras rumíes:

Margen superior:

$\mathcal{\varepsilon}=$ noventa $\quad,=$ siete (pesantes) $\quad+=$ uno y medio (dineros)

Fecha:
$d=$ mil
$\rho$ =quinientos
S = cincuenta
$\mathcal{J}=$ ocho 
a) Texto árabe

III (fol. 38r)

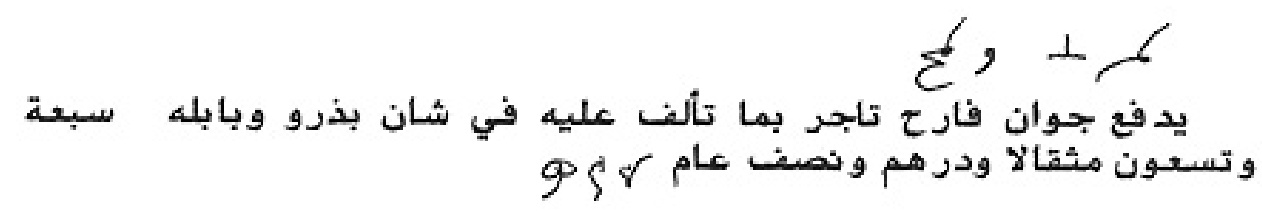

b) Texto castellano:

"Juan el Fireh y su hijo Miguel paguen en san Pedro y sant Pablo noventa y siete pesantes y un dinero y medio de los serviçios deste año de MDLIX años".

c) Traducción:

"Pague Juan Farihh, mercader, por lo que le corresponde en san Pedro y [san] Pablo noventa y siete meticales y un dirhem y medio. Año [1] 559".

d) Cifras rumíes:

Margen superior:

$$
\mathcal{E}=\text { noventa } \quad g=\operatorname{siete}(\text { pesantes }) \perp \_\quad \text { =uno y medio (dineros) }
$$

Fecha:

[..] $\quad \Phi=$ quinientos $\quad S=$ cincuenta $\quad \&$ =nueve

IV (fol. 44r.)

a) Texto árabe:
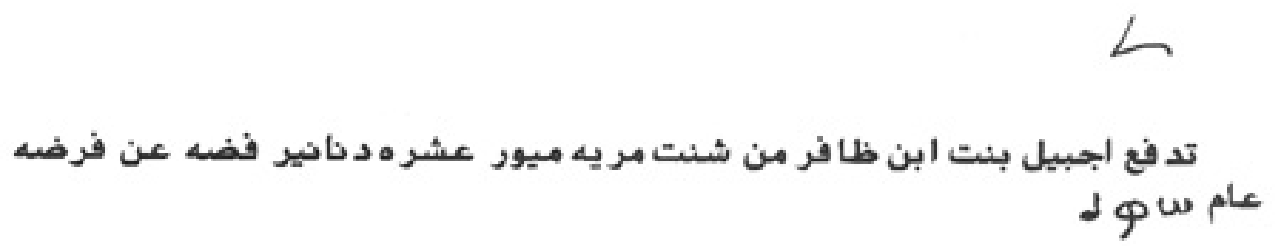

b) Texto castellano:

"Ysabel hija de Abendafir de santa Maria diez pesantes del serviçio deste año de DXX años".

c) Traducción:

"Pague Isabel bint Ibn Z̄āfir de Santa Maria Mayor diez dinares de plata por la farda. Año 1520".

d) Cifras rumíes:

Margen superior:

$\angle=\operatorname{diez}$ (pesantes)

Fecha:

$\boldsymbol{d}=$ mil $\quad \boldsymbol{\phi}=$ quinientos $\quad \boldsymbol{\omega}=$ veinte 


\section{RESUMEN}

Damos noticia, por vez primera, de la familia Ferí, considerándola parte de la oligarquía morisca granadina, en razón de su situación económica, de los privilegios que alguno de sus miembros tuvo por parte de la corona castellana y por la presencia de otros en acontecimientos políticos trascendentales.

\section{ABSTRACT}

For the first time we give notice about the Feri family, considering her a part of the moorish oligarchy of Granada because of her economic situation and the privileges which some of the members of the family had from the Crown of Castilla, and because the presence of the others members of the family in the most important political events. 